\title{
Hubungan Kualitas Kehidupan Kerja, Kepuasan Kerja, dan Integritas Akuntan Publik
}

\author{
Mila Hariani, Ella Anastasya Sinambela* \\ Fakultas Ekonomi, Manajemen, Universitas Mayjen Sungkono, Mojokerto, Indonesia \\ Email: ${ }^{1}$ milamasroni@gmail.com, 2,*easinambela@ gmail.com \\ Email Penulis Korespondensi: easinambela@gmail.com \\ Submitted: 22/11/2021; Accepted: 29/11/2021; Published: 30/11/2021
}

\begin{abstract}
Abstrak-Perkembangan profesi akuntan, khususnya akuntan publik di suatu negara, berjalan seiring dengan perkembangan bisnis di negara tersebut. Profesi ini memiliki tanggung jawab untuk meningkatkan tingkat kinerja laporan keuangan. Perhatian lebih harus diberikan kepada profesi akuntan. Begitu pun pada perilaku kerja mereka. Penelitian deskriptif dan korelasional ini menguji hubungan kualitas kehidupan kerja yang dirasakan akuntan publik beserta kepuasan kerja dan integritas. Alat analisis adalah korelasi dan dibantu dengan SPSS. Temuan menyebutkan hubungan antara kualitas kehidupan kerja dan kepuasan kerja ditemukan hubungan linier yang signifikan dan positif. Peningkatan kualitas kehidupan kerja menghasilkan peningkatan kepuasan kerja. Selain itu, hubungan antara kualitas kehidupan kerja dan integritas menunjukkan hubungan linier yang tidak signifikan dan positif antara kedua variabel. Begitu pun dengan hubungan kepuasan kerja dan integritas yang tidak ditemukan hubungan yang signifikan.
\end{abstract}

Kata Kunci: Kualitas Kehidupan Kerja; Kepuasan Kerja; Integritas; Akuntan Publik

\begin{abstract}
The development of the accounting profession, especially public accountants in a country, goes hand in hand with the development of business in that country. This profession has the responsibility to improve the level of financial reporting performance. More attention should be paid to the accounting profession. The same applies to their work behavior. This descriptive and correlational study examines the relationship between the perceived quality of work life of public accountants and job satisfaction and integrity. The analysis tool is correlation and assisted by SPSS. The findings mention the relationship between quality of work life and job satisfaction found a significant and positive linear relationship. Improving the quality of work life results in increased job satisfaction. In addition, the relationship between quality of work life and integrity shows an insignificant and positive linear relationship between the two variables. Likewise, the relationship between job satisfaction and integrity was not found to have a significant relationship.
\end{abstract}

Keywords: Quality of Work Life; Job Satisfaction; Integrity; Public Accountant

\section{PENDAHULUAN}

Tidak semua perusahaan dapat memberikan kenyamanan bagi pekerja yang dimilikinya. Sebagian pekerja merasa bahwa mereka telah diperlakukan tidak adil atau tidak layak di tempat kerja mereka. Di lain sisi, perusahaan akan mengalami kerugian bila mempekerjakan pekerja baru daripada mempertahankan pekerja yang ada (Koys, 2001; Frank et al., 2004).

Adanya kualitas kehidupan kerja di antara pekerja menjamin kebertahanan sebagai anggota organisasi perusahaan (Beauchamp \& Bowie, 2001; Ahmad, 2013). Pekerja sebagai karyawan yang puas cenderung memberikan produktivitas yang lebih besar, yang pada gilirannya meningkatkan kualitas pemberian layanan (Carter et al., 2013). Selain itu, kepuasan kerja secara keseluruhan seperti yang dialami oleh karyawan cenderung mencerminkan kombinasi dari kepuasan setiap unsur secara parsial terkait dengan berbagai fitur pekerjaan karyawan, seperti gaji, keamanan, pekerjaan itu sendiri, kondisi kerja dan jam kerja, yang semuanya mempengaruhi kualitas kehidupan kerja karyawan (Skalli et al., 2008). Oleh karena itu, kualitas kehidupan kerja karyawan berkontribusi terhadap kepuasan yang mereka alami di tempat kerja maupun dari pekerjaan itu sendiri (Sirgy et al., 2001). Ini menyebabkan menjadi menarik untuk mengamati bagaimana karyawan itu sendiri memandang kualitas kehidupan kerja mereka (Efraty \& Sirgy, 1990). Manajer mungkin memiliki pengaruh positif pada lingkungan kerja yang dapat mengarah pada produktivitas yang lebih besar dan tingkat penyampaian layanan berkualitas yang lebih tinggi yang diperoleh dari karyawan yang puas (Bell \& Menguc, 2002; Dhar, 2015; Lestari et al, 2021).

Kualitas kehidupan kerja didasarkan pada perasaan seseorang tentang keinginan tempat kerja dan segala apa yang ada di sana dan melampaui kepuasan dengan pekerjaan, kepuasan dalam domain kehidupan non-kerja dan kesejahteraan subjektif (Mobaraki et al., 2017). Kualitas kehidupan kerja berarti proses yang menanggapi kebutuhan karyawan dan memberikan kesempatan penuh untuk pengambilan keputusan dan perencanaan untuk kehidupan kerja mereka (Darmawan et al., 2020). Proses tersebut mencakup bagaimana bekerja sama dengan lebih baik, bagaimana memutuskan kegiatan mereka sendiri, mengubah dan meningkatkan apa yang dibutuhkan dan efektif untuk organisasi, memiliki integrasi dalam organisasi, mengarah pada pengembangan kemampuan manusia yang berbeda dan peluang untuk pertumbuhan dalam organisasi (Hamidi \& Mohamadi, 2012).

Kualitas kehidupan kerja diyakini menjadi indikator untuk memperhatikan kebutuhan manusia dan menempatkannya dalam konten kerja (Alzalabani, 2017). Cascio (2006) menyatakan ada dua cara dalam menjelaskan kualitas kehidupan kerja, yaitu sebagai seperangkat persepsi karyawan tentang keselamatan kerja, kepuasan kerja, dan kondisi untuk dapat tumbuh dan berkembang sebagai manusia dan sebagai seperangkat tujuan yang ingin dicapai melalui kebijakan organisasi seperti kondisi kerja yang aman, keterlibatan kerja, kebijakan 
pengembangan karir, kompensasi yang adil dan lain-lain. Menurut Othman dan Mok (2009), desain sistem kerja yang meningkatkan pengalaman kehidupan kerja anggota organisasi adalah kondisi umum untuk meningkatkan kualitas kehidupan kerja, sedangkan kebutuhan khusus adalah persepsi karyawan tentang kesejahteraan fisik dan psikologis mereka dalam tempat kerja.

Kepuasan kerja berarti tingkat kesenangan karyawan yang dirasakan setelah mengevaluasi hasil pekerjaannya (Ramawickrama et al., 2017) dan juga terkait dengan sikap karyawan di tempat kerja (Pio \& Tampi, 2018). Menurut Luthans (2006), dimensi kepuasan kerja adalah tanggapan emosional terhadap situasi kerja, seberapa baik hasil yang dicapai dan sikap yang berhubungan dengan pekerjaan. Dimensi kepuasan kerja juga mencakup jenis pekerjaan, upah, kesempatan promosi, supervisi pengawasan, dan rekan kerja di tempat kerja (Othman \& Mok, 2009).

Kepuasan kerja dalam organisasi dapat ditingkatkan melalui adanya kualitas kehidupan kerja yang baik antara karyawan dan pengusaha di suatu organisasi (Darmawan et al., 2021). Selain itu, lingkungan organisasi yang sesuai sangat efektif dalam memotivasi karyawan dan meningkatkan kerjasama sehingga dapat menjadi sumber penting dalam meningkatkan kreativitas kerja untuk memacu kepuasan kerja (Heidarie et al., 2012). Partisipasi karyawan dalam pengambilan keputusan serta memiliki kesempatan untuk berkembang akan dapat meningkatkan kepuasan kerja sehingga secara tidak langsung dapat meningkatkan kualitas kehidupan kerja (Sari et al., 2019).

Milliron (2008) menyatakan bahwa sifat transaksional, dikombinasikan dengan dorongan untuk produktivitas tenaga kerja, membuat pekerjaan bidang akuntansi rentan terhadap restrukturisasi. Lebih dari itu, pekerjaan seorang akuntan publik telah lama dilihat sebagai awal yang sangat baik untuk karir profesional, terutama karena memberikan pengalaman luas yang relevan dengan pasar, pelatihan dan paparan berbasis luas (Anderson-Gough et al., 2002; Almonte, 2009). Profesionalisme memerlukan peningkatan agar searah dengan pengembangan diri setiap anggota organisasi di tempat kerja (Ernawati et al., 2020). Meski demikian organisasi juga melakukan hal yang sama yaitu memberikan perhatian kepada kualitas kehidupan kerja.

Ini menempatkan akuntan dalam sorotan pertanyaan untuk kualitas kehidupan kerja mereka, mengingat slogan manajemen sumber daya manusia bahwa biayanya jauh lebih besar untuk mengganti dan melatih karyawan baru daripada mempertahankan yang sudah ada, yang ada di antara sebagian besar akuntan (Frank et al., 2004).

Menurut Bushman \& Smith (2001), akuntan publik, yang terdiri dari fungsi audit dan review, menambah kredibilitas informasi keuangan. Fungsi yang paling menonjol adalah pemeriksaan independen atas laporan keuangan perusahaan dan dokumen pendukungnya (Bazerman et al., 1997). Akuntansi manajemen adalah kategori utama lainnya dalam layanan akuntansi yang memberikan saran dan arahan bisnis tentang keputusan strategis, taktis, dan operasional dengan memanfaatkan data keuangan. Layanan akuntansi lainnya meliputi: pembukuan, persiapan pajak penghasilan, penilaian bisnis, akuntansi forensik, kepatuhan pajak, konsultasi investasi, organisasi sistem akuntansi dan desain dan jasa konsultasi manajemen.

Woelfel (1986) menyatakan ada hal utama untuk tetap dijaga oleh akuntan saat mengerjakan tugas agar tetap berkualitas dan bebas intervensi dari kepentingan dengan memerhatikan faktor integritas maupun objectivitas. Tidak ada keberpihakan maupun kesalahan. Seringkali akuntan publik mengalami dilema etika yang melibatkan nilai-nilai yang bertentangan dengan standar etika profesi yang pada akhirnya memudarkan prinsip-prinsip etika yang harus ditegaskan, yaitu integritas. Integritas menjadi salah satu prinsip etika utama yang harus dipahami dan dilaksanakan oleh setiap akuntan (Smith \& Bain, 1990). Integritas adalah misi atau tujuan bersama untuk tumbuh dan berkembang dalam hati nurani setiap individu. Finn et al. (1988) menyatakan ada tiga faktor utama dari integritas, yaitu kejujuran, tanpa ada kepentingan, dan tidak ada kesalahan pada penyajian materi.

Profesi ini memiliki harapan dari semua pihak seperti investor, kreditur, pemerintah, hingga masyarakat. Penilaian secara transparan dan objektivitas tanpa membawa kepentingan tertentu adalah mutlak diperlukan. Akuntan wajib memiliki prinsip etika yaitu integritas. Mereka harus jujur serta tegas untuk melakukan tugas audit. Dengan memiliki integritas maka akuntan mungkin boleh memahami error tanpa sengaja serta gap dari pernyataan yang jujur. Namun mereka harus menolak tentang segala bentuk kecurangan prinsip. Adanya integritas menjadikan mereka taat terhadap standar teknis dan etika. Selain itu komitmen akan dibutuhkan dalam integritas yang akan dipengaruhi lingkungan kerja yang kondusif (Jahroni et al, 2021; Putra \& Mardikaningsih, 2021).

Dengan demikian, tujuan dari studi ini adalah untuk memastikan bagaimana perusahaan di setiap kantor akuntan publik dan manajemennya sejauh ini dalam mempraktikkan terapan secara manajerial yang sesuai, dan apakah tingkat yang dinilai ada hubungannya dengan kualitas kehidupan kerja, kepuasan kerja, dan integritas dari akuntan publik yang dipekerjakannya.

\section{METODE PENELITIAN}

Penelitian ini menggunakan metode deskriptif dan korelasional. Metode penelitian deskriptif berkaitan dengan prosedur yang digunakan untuk mengatur, menggambarkan dan meringkas data, sedangkan desain korelasional menggambarkan hubungan statistik antara dua atau lebih variabel. Desain ini sesuai karena tujuan penelitian ini adalah untuk menguji hubungan kepuasan kerja yang dirasakan akuntan publik beserta kualitas kehidupan kerja dan integritas.

Data primer dikumpulkan melalui penggunaan kuesioner survei yang dibagikan kepada akuntan publik yang saat ini bekerja baik sebagai analis akun, akuntan perusahaan, atau auditor perusahaan besar di Surabaya. Karena 
keterbatasan hanya diperoleh ukuran sampel kecil meski dengan upaya besar. Ada 27 akuntan dipertimbangkan dalam pengumpulan data, namun hanya 23 akuntan yang dimasukkan dalam analisis akhir. Instrumen penelitian tersusun dengan menggunakan instrumen berupa angket dan skala, yang meliputi: Quality of Worklife Scale dari O'Connell dan Russell (2008), yang digunakan untuk mengukur kualitas kehidupan kerja dalam dua indikator: kondisi kerja dan hubungan kerja. Survei Kepuasan Kerja (Job Satisfaction Survey/JSS) dikembangkan oleh Spector (1985). Ini adalah instrumen mapan yang digunakan untuk mengevaluasi aspek kepuasan kerja. Ada tujuh subskala: gaji, promosi, pengawasan, sifat pekerjaan, penghargaan kontingen, rekan kerja dan komunikasi. Integritas diukur dengan empat sikap yaitu kejujuran dan transparan, berani, bijaksana, dan bertanggung jawab (Putra, 2019). Korelasi Pearson Product Moment digunakan untuk mengetahui hubungan antara kepuasan kerja, kualitas kehidupan kerja dengan integritas.

\section{HASIL DAN PEMBAHASAN}

Ada 23 responden meliputi 17 pria dan 6 perempuan. Usia antara 29 hingga 48 tahun. Pengalaman kerja antara 1 hingga 5 tahun sebanyak 9 orang, dan sisanya lebih dari lima tahun. Angket yang dibagikan kepada responden diuji melalui uji validitas dan reliabilitas untuk mengetahui kualitas data.

Butir pernyataan di angket dicek dengan item total corrected correlation. Hasil menunjukkan semua telah valid. Reliabilitas berdasar crohbach alpha 0,7. Hasil diperoleh untuk kualitas kehidupan kerja adalah 0,864 , untuk kepuasan kerja adalah 0,778 , dan untuk integritas adalah 0,635. Ketiga variabel sudah reliabel.

Output SPSS pada uji korelasi variabel antara kualitas kehidupan kerja dan kepuasan kerja $(0,005)$, kualitas kehidupan kerja dan integritas $(0,097)$, dan kepuasan kerja dan integritas $(0,863)$. Nilai signifikan diperbandingkan dengan 0,05 . Hanya ada korelasi secara nyata dari kualitas kehidupan kerja dan kepuasan kerja. Sisanya tidak signifikan. Koefisien korelasi antara kualitas kehidupan kerja dan kepuasan kerja sebesar 0,783. Ini berarti korelasi keduanya searah dan positif. Semakin berkualitas kehidupan kerja maka responden merasa semakin puas dalam pekerjaan. Semakin rendah kualitas kehidupan kerja maka menyebabkan responden merasa tidak puas dengan pekerjaan. Kedua variabel tersebut memiliki korelasi yang kuat.

Temuan menyebutkan bahwa kualitas kehidupan kerja memiliki hubungan positif dan signifikan terhadap kepuasan kerja. Ini sesuai dengan Fatehi et al. (2015). Dorongan karyawan untuk bertahan dan bertahan juga dapat dimotivasi oleh kualitas kehidupan kerja yang baik. Faktor lain yang dapat mempengaruhi kinerja karyawan adalah kepuasan kerja (Darmawan et al, 2021). Dengan demikian, keberhasilan akuntan mungkin ditentukan oleh kualitas kehidupan kerja. Kualitas kehidupan kerja menentukan kepuasan kerja. Bila KAP menginginkan kinerja akuntan meningkat, maka KAP perlu meningkatkan kepuasan kerja mereka. Temuan lain menyebutkan bahwa tidak ada hubungan yang signifikan antara kualitas kehidupan kerja dan integritas. Begitu pun antara kepuasan kerja dan integritas.

\section{KESIMPULAN}

Hubungan antara kualitas kehidupan kerja dan kepuasan kerja ditemukan hubungan linier yang signifikan dan positif antara kedua variabel, yang menyiratkan bahwa peningkatan kualitas kehidupan kerja menghasilkan peningkatan kepuasan kerja. Selain itu, hubungan antara kualitas kehidupan kerja dan integritas menunjukkan hubungan linier yang tidak signifikan dan positif antara kedua variabel. Begitu pun dengan hubungan kepuasan kerja dan integritas yang tidak ditemukan hubungan yang signifikan. Dengan demikian, hubungan yang perlu diperhatikan adalah antara kualitas kehidupan kerja dan kepuasan kerja. Cara paling umum untuk meningkatkan kualitas kerja dan kehidupan adalah keterlibatan akuntan. Keterlibatan mereka mencakup berbagai metode sistematis bagi karyawan untuk berpartisipasi dalam pengambilan keputusan dan hubungan mereka dengan pekerjaan, tugas, dalam keorganisasian. Dengan bekerja keras untuk melibatkan mereka dalam pengambilan keputusan secara manajerial, merekaakan merasa bertanggung jawab dan memunculkan rasa memiliki. Ini memunculkan rasa puas pada diri mereka. Selain itu, KAP harus memberikan fasilitas pengembangan kompetensi untuk memecahkan masalah dalam organisasinya sehingga akuntan merasa termotivasi untuk meningkatkan kinerja mereka dalam organisasi. Para akuntan harus menghasilkan kinerja berkualitas. Ini juga harus ditunjang oleh kompetensi, pengalaman dan pengetahuan (Arifin \& Darmawan, 2021). Harapan yang ada agar kepercayaan publik muncul dari pemeriksaan yang berkualitas. Nilai integritas harus dimiliki oleh akuntan dalam bentuk kepatuhan tanpa tawar terhadap kode etik dan moral. Selain itu memboikot segala bentuk penipuan dan pemalsuan. Akuntan memiliki tanggung jawab agar memberi nilai tambah laporan keuangan perusahaan. Dengan demikian klien mendapatkan nilai berupa informasi keuangan yang terpercaya.

\section{REFERENCES}

Ahmad, S. (2013). Paradigms of Quality of Work Life. Journal of Human Values,19(1), 73-82.

Almonte, E. (2009). Exercising Leadership. Journal of Accountancy, 207(1), 54.

Alzalabani, A. H. (2017). A Study on Perception of Quality of Work-life and Job Satisfaction: Evidence from Saudi Arabia. Arabian Journal of Business and Management Review, 7(2), 1-9. 
Anderson-Gough, F., C. Grey., \& K. Robson. (2002). Accounting Professionals and the Accounting Profession: Linking Conduct and Context. Accounting and Business Research, 32(1), 41-56.

Arifin, S. \& D. Darmawan. (2021). Studi tentang Pengalaman Kerja, Komitmen Kerja, Dukungan Organisasi dan Pengaruhnya terhadap Kinerja Karyawan, Jurnal Edunomika, 6(1), 33-43.

Bazerman, M. H., K. P. Morgan., \& G.F. Loewenstein. (1997). The Impossibility of Auditor Independence. MIT Sloan Management Review, 38(4), 89.

Beauchamp, T., \& N. E. Bowie. (2001). Ethical Theory and Business. Prentice Hall Upper Saddle River.

Bell, S. J., \& B. Menguc. (2002). The Employee-Organization Relationship, Organizational Citizenship Behaviors, and Superior Service Quality. Journal of Retailing, 78(2), 131-146.

Bushman, R. M., \& A. J. Smith. (2001). Financial Accounting Information and Corporate Governance. Journal of Accounting and Economics, 32(1), 237-333.

Carter, M. Z., A. A. Armenakis., H. S. Feild., \& K. W. Mossholder. (2013). Transformational Leadership, Relationship Quality, and Employee Performance During Continuous Incremental Organizational Change. Journal of Organizational Behavior, 34(7), 942-958.

Cascio, W. F. (2006). Managing Human Resources: Productivity, Quality of Work-Life, Profits. Edited by 2en ed. New York: McGraw-Hill.

Darmawan, D et al. (2020). The Quality of Human Resources, Job Performance and Employee Loyalty, International Journal of Psychosocial Rehabilitation, 24(3), 2580-2592.

Darmawan, D., E. A. Sinambela, M. Hariani, \& M. Irfan. (2020). Analisis Komitmen Organisasi, Iklim Kerja, Kepuasan Kerja dan Etos Kerja yang Memengaruhi Kinerja Pegawai, Jurnal Bisnis dan Kajian Strategi Manajemen, 4(1), 58-70.

Darmawan, D., R. Mardikaningsih, S. Arifin, E. A. Sinambela, \& A. R. Putra. (2021). Studi tentang Peranan Variabel Kompetensi, Penilaian Kinerja, dan Kondisi Kerja terhadap Perwujudan Kepuasan Kerja Guru, Jurnal Pendidikan dan Kewirausahaan, 9(2), 516-530.

Dhar, R. L. (2015). Service Quality and the Training of Employees: The Mediating Role of Organizational Commitment. Tourism Management, 46, 419-430.

Efraty, D., \& M. J. Sirgy. (1990). The Effects of Quality of Working Life (QWL) on Employee Behavioral Responses. Social Indicators Research, 22(1), 31-47.

Ernawati, E. A. Sinambela, R. Mardikaningsih, \& D. Darmawan. (2020). Pengembangan Komitmen Organisasi melalui Profesionalisme Karyawan dan Kepemimpinan yang Efektif, Jurnal Ekonomi dan Ekonomi Syariah, 3(2)

Fatehi, B., A. Karimi., E. G. Pour., K. A. Pour., \& B. Azizi. (2015). Impact of Quality of Work Life on Job Satisfaction. International Journal of Sport Studies, 5(1), 79-86.

Finn, D. W., L. B. Chonko \& S. D. Hung. (1988). Ethical Problems in Public Accounting: The View from the Top. Journal of Business Ethics (Netherlands), 7(8), 605-615.

Frank, F. D., R. P. Finnegan., \& C. R. Taylor. (2004). The Race for Talent: Retaining and Engaging Workers in the 21st century. People and Strategy, 27(3), 12.

Hamidi, F., \& B. Mohamadi. (2012). Teachers Quality of Work-life in Secondary Schools. International Journal of Vocational and Technical Education, 4(1), 1-5.

Heidarie, A., A. Parviz., S. Sara., \& G. Bahman. (2012). Relationship between Quality of Work-life, Organizational Health and Commitment with Job Satisfaction. Life Science Journal, 9(3), 2300-06.

Jahroni, D. Darmawan, R. Mardikaningsih, \& E. A. Sinambela. (2021). Peran Insentif, Perilaku Kepemimpinan, dan Budaya Organisasi terhadap Penguatan Komitmen Organisasi, Jurnal Ekonomi dan Ekonomi Syariah, 4(2), 1389-1397.

Koys, D. J. (2001). The Effects of Employee Satisfaction, Organizational Citizenship Behavior, and Turnover on Organizational Effectiveness: A Unit-Level, Longitudinal Study. Personnel Psychology, 54(1), 101- 114.

Lestari, U. P., E. A. Sinambela, R. Mardikaningsih, \& D. Darmawan. (2020). Pengaruh Efikasi Diri dan Lingkungan Kerja terhadap Kepuasan Kerja Karyawan, Jurnal Ekonomi dan Ekonomi Syariah, 3(2), 529-536.

Luthan, F. (2006). Perilaku Organisasi, Edisi Kesepuluh. Yogyakarta. ANDI.

Milliron, V. C. (2008). Exploring Millennial Student Values and Societal Trends: Accounting Course Selection Preferences. Issues in Accounting Education,23(3), 405-419.

Mobaraki, H., G. M. Rokhsare., M. Kamali., \& A. Pourbakht. (2017). The Relationship between Quality of Work-life and Job Satisfaction among Audiologists in Iran. Auditory and Vestibular Research, 26(4), 215-22.

O'Connell, P. J., \& H. Russell. (2008). Employment and the Quality of Work.In Quality of Life in Ireland (pp. 43-66). Springer Netherlands.

Othman, A., \& C. Lieng Mok. (2009). Relationship between Quality of Work-life (Qwl) and Job Satisfaction: A Case Study of Enterprise "Xyz" in Malacca. International Conference on Human Capital Development (ICONHCD). 25-27 May. Kuantan, Pahang, 1-6.

Pio, R. J., \& J. R. E. Tampi. (2018). The Influence of Spiritual Leadership on Quality of Work-life, Job Satisfaction and Organizational Citizenship Behavior. International Journal of Law and Management, 60(2), 757-767.

Putra, A. R., E. Retnowati \& E. A. Sinambela. (2019). Pengaruh Komunikasi Kerja dan Integritas terhadap Kinerja Pegawai. Ebis, Jurnal Ekonomi Bisnis, 12(1), 23-34.

Putra, A. R., \& R. Mardikaningsih. (2021). Kompensasi dan Lingkungan Kerja serta Pengaruhnya terhadap Komitmen Organisasi, Jurnal Edunomika, 6(1), 44-53.

Ramawickrama, J., H. H. D. N. P. Opatha., \& M. D. PushpaKumari. (2017). Quality of Work-life, Job Satisfaction, and the Facets of the Relationship between the Two Constructs. International Business Research, 10(4), 167-182.

Sari, N. P. R., I. K. G. Bendesa, I., \& M. Antara. (2019). The Influence of Quality of Work-life on Employees' Performance with Job Satisfaction and Work Motivation as Intervening Variables in Star-Rated Hotels in Ubud Tourism Area of Bali. Journal of Tourism and Hospitality Management, 7(1), 74-83.

Sirgy, M. J., D. Efraty., P. Siegel., \& D. J. Lee. (2001). A New Measure of Quality of Work Life (QWL) Based on Need Satisfaction and Spillover Theories. Social indicators research, 55(3), 241-302. 
Ekonomi, Keuangan, Investasi dan Syariah (EKUITAS)

Vol 3, No 2, November 2021, Hal 297-301

ISSN 2685-869X (media online)

DOI 10.47065/ekuitas.v3i2.1151

Skalli, A., I. Theodossiou., \& E. Vasileiou. (2008). Jobs as Lancaster Goods: Facets of Job Satisfaction and Overall Job Satisfaction. The Journal of Socio-Economics, 37(5), 1906-1920.

Smith, L. M., \& C. Bain. (1990). The Challenge of Professional Accounting Ethics. Internal Auditing, 5(4), $20-31$.

Spector, P. E. (1985). Measurement of Human Service Staff Satisfaction: Development of the Job Satisfaction Survey. American Journal of Community Psychology, 13(6), 693-713.

Woelfel, C. J. (1986). Standards of Ethical Conduct for Management Accountants. Journal of Business Ethics (Netherlands), $5(5), 365-371$. 